https://helda.helsinki.fi

Competition between a toxic and a non-toxic Microcystis strain under constant and pulsed nitrogen and phosphorus supply

\title{
Suominen, Saara
}

2017-03

Suominen , S , Brauer , V S , Rantala-Ylinen , A , Sivonen , K \& Hiltunen , T 2017 , '

Competition between a toxic and a non-toxic Microcystis strain under constant and pulsed

nitrogen and phosphorus supply ' , Aquatic Ecology , vol. 51 , no. 1 , pp. 117-130 . https://doi.org/10.1007/s10452-01

http://hdl.handle.net/10138/307949

https://doi.org/10.1007/s10452-016-9603-2

unspecified

acceptedVersion

Downloaded from Helda, University of Helsinki institutional repository.

This is an electronic reprint of the original article.

This reprint may differ from the original in pagination and typographic detail.

Please cite the original version. 


\section{Competition between a toxic and a non-toxic Microcystis strain}

\section{2 under constant and pulsed nitrogen and phosphorus supply}

4 Saara Suominen $^{1 \dagger}$, Verena S. Brauer ${ }^{2,3,4 \dagger}$, Anne Rantala-Ylinen ${ }^{1}$, Kaarina Sivonen $^{1}$ and Teppo $5 \quad$ Hiltunen $^{1 *}$

$7 \quad{ }^{1}$ Department of Food and Environmental Sciences / Microbiology and Biotechnology

8 P.O. Box 65, 00014 University of Helsinki, FINLAND

$9 \quad{ }^{2}$ Department of Aquatic Microbiology, Institute for Biodiversity and Ecosystem Dynamics, University 10 of Amsterdam, P.O. Box 94248, 1090 GE Amsterdam, THE NETHERLANDS

$11{ }^{3}$ Groningen Institute for Evolutionary Life Sciences, University of Groningen, Nijenborgh 7, 9747 AG 12 Groningen, THE NETHERLANDS

13 Present address: Aquatic Microbiology, Biofilm Centre, University of Duisburg-Essen, 14 Universitätsstr. 5, 45141 Essen, GERMANY

$15{ }^{\dagger}$ Equal contribution

$16 \quad{ }^{*}$ Corresponding author teppo.hiltunen@helsinki.fi

17 Running head: Genotype dynamics in experimental Microcystis populations

18 Keywords: algal toxins, Droop model, harmful cyanobacteria, nutrient limitation, microcosm,

19 Microcystis aeuruginosa, plankton dynamics, resource pulses, quantitative PCR 


\section{Abstract}

21 The toxicity of a harmful algal bloom is strongly determined by the relative abundance of

22 non-toxic and toxic genotypes, and might therefore be regulated by competition for growth-

23 limiting resources. Here, we studied how the toxic Microcystis aeruginosa strain PCC 7806

24 and a non-toxic mutant compete for nitrogen and phosphorus under constant and pulsed

25 nutrient supply. Our monoculture and competition experiments show that these closely

26 related genotypes have distinct nutrient physiologies and that they differ in their ability to

27 compete for nitrogen and phosphorus. The toxic wild type won the competition under

28 nitrogen limitation, while the non-toxic mutant dominated under phosphorus limitation.

29 Pulses of both nitrogen and phosphorus increased the dominance of the toxic genotype, which

30 lead to an even faster competitive exclusion of the non-toxic genotype under nitrogen pulses

31 and to coexistence of both genotypes under phosphorus pulses. Our findings indicate that the

32 genotype level dynamics driven by resource competition can be an important factor in

33 determining cyanobacterial bloom toxicity. 
The harmful blooms of microalgae and cyanobacteria (harmful algal blooms, HABs) that often form in eutrophic freshwater and estuaries are among the most eye-catching and problematic microbial populations found in nature (Paerl and Otten, 2013; Brooks et al., 2015). These microbial mass occurrences are of great societal relevance because they threaten the production of drinking water and the recreational use of water bodies. It has been predicted that global change will further increase the risk and intensity of HABs due to human-induced eutrophication (O’Neil et al., 2012; Mantzouki et al., 2015), global warming (Paerl and Huisman, 2008, 2009), increased water column stratification (Jöhnk et al., 2008), and rising $\mathrm{CO}_{2}$ levels (Verspagen et al., 2014).

Although HABs are often dominated by a single species, they harbour substantial genetic diversity and can vary considerably in toxicity. It has been shown that the toxicity of a bloom depends to a large extent on the relative proportions of toxic versus non-toxic or less toxic strains or genotypes of the same species (e.g. Park et al., 1998; Chorus et al., 2001; Briand et al., 2002; Wiedner et al. 2002; Welker et al., 2003; Huisman et al., 2005). The difference in toxin production level between genotypes can cover several orders of magnitude and exceeds by far the within-genotype variability in toxin production caused by environmental factors (Sivonen and Jones, 1999; Rohrlack et al., 2001; Carrillo et al., 2003). Several studies have indicated that the temporal and spatial distribution of toxic and nontoxic genotypes within natural blooms could be explained as the result of resource competition. For instance, Kardinaal et al. (2007) demonstrated in laboratory experiments that a toxic genotype of the harmful cyanobacterium Microcystis aeruginosa was displaced by a non-toxic type under light limitation. The authors suggested that the transition from toxic to non-toxic Microcystis genotypes during the duration of a bloom could be explained by the development of high biomass concentrations toward the end of the bloom, which 
increases self-shading and enhances competition for light. Furthermore, van de Waal et al. (2011) demonstrated that the same non-toxic strain of Microcystis outcompeted the toxic strain in $\mathrm{CO}_{2}$-limited conditions. Yet, $\mathrm{HABs}$ are also known to be affected by limitation of nutrients, in particular, nitrogen and phosphorus. If toxic and non-toxic genotypes differ in their competitive ability for these two nutrients, the type of nutrient limitation that arises might strongly influence the toxicity of a bloom. Nitrogen and phosphorus limitation may occur towards the end of blooms, but these have also been observed during earlier phases (Moisander et al., 2003; Walve and Larsson, 2007; Davis et al., 2009). Earlier periods of nutrient limitation may be interrupted by pulses of nutrient supply, for example, when windinduced mixing of the water column enhances the diffusive inflow of nutrients from deeper water layers (Kononen et al., 1996; Stal et al., 1999; Davis et al., 2009). In fact, it has been argued that in natural systems such fluctuations in nutrient availability are the rule rather than the exception (e.g. Grover, 1988, 1991; Padisák, et al., 1993; Sommer 2002). Thus, if toxic and non-toxic genotypes also differ in their abilities to exploit nutrient pulses, the intensity of nutrient fluctuations might represent an additional important factor that influences how the toxin content of the bloom develops.

In this study, we used controlled microcosm experiments to investigate the competition between a toxic and a non-toxic strain (hereafter interchangeably also referred to as genotypes) of the harmful cyanobacterium Microcystis aeruginosa for nitrogen and phosphorus under both constant and pulsed supply. First, we measured several growth parameters for each genotype in replicated monocultures. Second, we investigated the competition between both genotypes under constant nutrient supply and under different kinds of nutrient pulses in replicated continuous and semi-continuous cultures. We also applied a parameterized Droop model to study the competition for phosphorus under constant and pulsed conditions in more detail with the help of numerical computer simulations. 


\section{Methods}

\section{Microcystis strains and culture maintenance:}

We investigated the competition between two axenic strains (hereafter genotypes) of $M$. aeruginosa: the toxic (microcystin-producing) wild type (WT) PCC 7806, obtained from the Pasteur Culture Collection in Paris, and the non-toxic mutant genotype (M), provided by Prof. E. Dittmann. The mutant genotype was originally generated from the PCC 7806 by inserting a chloramphenicol resistance cartridge into the $m c y B$ gene involved in microcystin biosynthesis (Dittmann et al., 1997). Axenic pre-cultures of both genotypes were grown at 25 $\pm 1^{\circ} \mathrm{C}$ in a $250 \mathrm{~mL}$ Erlenmeyer flask containing $40 \mathrm{~mL}$ of $\mathrm{Z} 8$ growth medium (Kotai, 1972). Z8 growth medium was prepared with analytical grade water $\left(\right.$ ELIX $^{\circledR}$, Merck Millipore, Billerica, MA, USA). Stock cultures of the mutant genotype also contained $5 \mu \mathrm{g}$ chloramphenicol $\mathrm{mL}^{-1}$ (Dittmann et al., 1997).

\section{Total Microcystis cell densities:}

The Microcystis populations in our study exhibited a linear relationship between cell density and optical density (OD), as shown previously (Briand et al., 2012). We therefore established a standard conversion formula to estimate cell density as a function of OD. To achieve this, cell numbers of live samples from a chemostat culture at steady state were counted with a hemacytometer counting chamber using a compound microscope (Zeiss Axioskop 2 plus, Oberkochen, Germany). OD was measured at the wavelength $750 \mathrm{~nm}$ (UV-1800 spectrophotometer, Shimadzu, Japan). In the range of OD values that we observed in our experiments $(0.01-0.25)$, the cell density of Microcystis (cells $\mathrm{mL}^{-1}$ ) could be reliably estimated according to the following linear regression equation: density (cells $\mathrm{mL}^{-1}$ ) $=\mathrm{OD}_{750}$ $\times 4 \times 10^{7}\left(N=7 ; R^{2}=0.949\right)$. 
110 Relative genotype proportions:

111 We sampled our microcosms every 1-3 days, depending on the experiment, with sterile

112 syringe (chemostats) or pipette (batch cultures). Note that not all the samples were analyzed

113 in the end. We used quantitative real-time PCR (qPCR) for quantifying genotype proportions

114 in our experimental samples. We followed previously published general protocols for the

115 Microcystis system (Briand et al. 2009, 2012; Kurmayer and Kutzenberger, 2003). In our

116 study, DNA was extracted using the DNeasy Plant Mini Kit (Qiagen). Extractions were

117 diluted 10-fold for qPCR, which was used to estimate the proportion of the mutant genotype.

118 All cells in the culture were quantified with previously described primers and a probe for an

119 intergenic spacer in the phycocyanin (PC) gene (Briand et al., 2009, 2012; Kurmayer and

120 Kutzenberger, 2003). The primers and the probe used to quantify the mutant strain targeted

121 the inserted chloramphenicol resistance cassette in the $m c y B$ gene (Briand et al., 2012). The

122 probes were labeled with the fluorescent reporter dye FAM (6-carboxyfluorescein) at the 5'

123 end and the amidite Black Hole Quencher-1 (BHQ-1) at the 3'end. qPCR was performed with

124 Applied Biosystems 7300 RealTime PCR Systems (Life Technologies). The PCR reactions

125 contained $10 \mu 1$ of the PerfeCta FastMix ${ }^{\circledR}$ II supermix with ROX ${ }^{\mathrm{TM}}$ (Quanta Biosciences), 200

$126 \mathrm{nM}$ of forward and reverse primers, $100 \mathrm{nM}$ of probe and $5 \mu 1$ of template DNA in a total

127 volume of $20 \mu \mathrm{l}$. The PCR was performed with a 2-step PCR program. The PCR program

128 included initial denaturation for $3 \mathrm{~min}$ at $95{ }^{\circ} \mathrm{C}$, followed by 40 cycles of $15 \mathrm{~s}$ at $95^{\circ} \mathrm{C}$ and 1

129 minute at $60{ }^{\circ} \mathrm{C}$. All PCR reactions were performed in triplicates, including negative

130 reactions not containing DNA template and a positive control containing $50 \%$ mutant cells,

131 which was used to normalize results. The fluorescence threshold value was manually set to

1320.15 in all qPCR runs while baseline values were determined automatically. The proportion

133 of mutant strain related to all cells was determined using the $\Delta \mathrm{Ct}$ method first developed by

134 Briand et al. (2008) for Planktothrix agardhii and subsequently used for M. aeruginosa 
135 (Briand et al., 2009, 2012; Sabart et al., 2010). Further details of the qPCR protocol can be

136 found from the supplementary information file.

138 Monoculture parameters:

139 As a first step, we used monoculture experiments to determine several growth parameters for

140 each genotype. These parameters allow to make predictions about the outcome of

141 competition in mixed culture, which can then be compared to the results from the competition

142 experiments. The monoculture parameters will also be used to parameterize a variable-

143 internal-stores model of competition.

145 Realized maximum specific growth rate: For each genotype, the maximum specific growth 146 rate, $\mu_{\max }$, was determined in semi-continuous cultures $(\mathrm{n}=6)$ on N-limited and P-limited

147 growth medium, respectively. Cultures of $100 \mathrm{~mL}$ were inoculated with very low cell density 148 and grown in $250 \mathrm{~mL}$ Erlenmeyer flasks for three days. Every day, $10 \%$ of the culture was 149 replaced with fresh growth medium and the cell density, $N_{t}$, at time point $t$ was determined.

150 The maximum specific growth rates in N-limited and P-limited growth medium, $\mu_{\max , N}$ and $151 \mu_{\max , P}$, were calculated as the mean of the two growth rates calculated between the two time 152 intervals as $\ln \left(N_{t+1} / N_{t}\right) /(t)+d$, where $d$ represents the dilution rate of 0.1 day $^{-1}$.

154 Critical nutrient concentrations: In order to measure the critical resource concentration for nitrogen, $R_{N}^{*}$, and phosphorus, $R_{P}^{*}$, each genotype was grown separately in chemostats $(\mathrm{n}=$ 3) for approximately three weeks until it reached a steady state. The $R_{N}^{*}$ and $R_{p}^{*}$ values of each genotype were then determined as the residual nutrient concentration in the nitrogenand phosphorus-limited steady state, respectively. Nutrient analysis was based on triplicate samples of $50 \mathrm{~mL}$ that were taken from the steady state cultures and centrifuged at $8000 \times \mathrm{g}$ 
160 and $4^{\circ} \mathrm{C}$ for 5 minutes in order to remove Microcystis cells. The supernatant was then filtered 161 through a $0.22 \mu \mathrm{m}$ filter with Supor $^{\circledR}$ membrane (Merck Millipore, Billerica, MA, USA) and

162 stored at $-20{ }^{\circ} \mathrm{C}$. Analyses of $\mathrm{N}$ and $\mathrm{P}$ were conducted at Lammi Biological Station 163 (University of Helsinki) with the following methodology: total dissolved nitrogen and 164 phosphorus were analyzed by flow injection analysis (FIA) colorimetry (Quikchem8000, 165 Lachat Instruments, Hach Company, Loveland, CO, USA) using the alkaline persulfate oxidation method (QuikChem ${ }^{\circledR}$ METHOD 10-107-04-1-I, Lachat Instruments, Hach

167 Company, Loveland, CO, USA) for nitrogen concentrations and the alkaline persulfate 168 digestion method (QuikChem ${ }^{\circledR}$ METHOD 10-115-01-1-S, Lachat Instruments, Hach 169 Company, Loveland, CO, USA) for phosphorus concentrations, respectively.

Minimum nutrient quota: The minimum quotas for nitrogen and phosphorus, $Q_{\min , N}$ and $Q_{\min , P}$, of each genotype was determined as the intracellular nutrient concentration measured from cells obtained from each chemostat on two separate days, one week apart, when the

174 culture had reached steady state. $50 \mathrm{~mL}$ of culture was collected and centrifuged at $10000 \times$ $175 \mathrm{~g}$ and $4{ }^{\circ} \mathrm{C}$ for 5 minutes. The supernatant was removed from the cells and $3 \mathrm{~mL}$ of type-2 analytical grade water $\left(\right.$ ELIX ${ }^{\circledR}$, Merck Millipore, Billerica, MA, USA) was used to resuspend the cells. A volume of $1.5 \mathrm{~mL}$ of the cell solution was collected into a $2 \mathrm{~mL}$ tube and stored at $-20{ }^{\circ} \mathrm{C}$. Nutrients were analysed at a later stage as described in the paragraph

179 above on critical nutrient concentrations.

Maximum nutrient uptake rates: To measure the maximum phosphorus uptake rate, $50 \mathrm{~mL}$ of

182 a P-depleted culture was added in $500 \mathrm{ml}$ of growth medium containing $25 \mu \mathrm{mol} \mathrm{L}{ }^{-1}$ of 183 phosphate. The reduction in dissolved phosphorus concentration was then monitored after 0 , $1842,4,6$ and 24 hours. Plotting the external phosphorus concentrations versus time revealed an 
185 initial linear phase so that the maximum P-uptake rate was estimated by linear regression as

186 the absolute value of the slope. Unfortunately, due to technical problems, the experiments to

187 measure the maximum uptake rate of nitrogen failed so that this rate could not be determined.

189 Maximum nutrient quota: Maximum intracellular nitrogen and phosphorus quotas, $Q_{\max , N}$ and

$190 Q_{\max , P}$, were determined by culturing cells in $250 \mathrm{~mL}$ Erlenmeyer flasks containing Z8 culture medium with nitrogen and phosphorus in non-limiting concentrations (Kotai 1972). Cultures were grown for three days before cells were collected for nutrient measurements. $50 \mathrm{~mL}$ of the sample was centrifuged at $8000 \times \mathrm{g}$ and $4{ }^{\circ} \mathrm{C}$ for 5 minutes. The supernatant was removed as precisely as possible, and cells were washed three times with $50 \mathrm{~mL}$ of type- 2 analytical grade water and the sample was stored frozen in $-20{ }^{\circ} \mathrm{C}$. Nitrogen and phosphorus concentrations were analysed at a later stage as described for critical nutrient concentrations. Uptake rate and nutrient quota parameters are based on values obtained from a single microcosm.

Half-saturation constant: The half-saturation constant for phosphorus uptake for each genotype, $K_{i}$, was estimated by optimizing the numerical solution to the model described in the methods section further below (eq. 1-3). The model was first solved by using the function lsoda of the R-package deSolve, which automatically switches between stiff and non-stiff

204 integration methods (Soetaert et al., 2010). The model predictions were then fit to the data

205 from the monoculture experiments by minimizing the residual sum of squares with the help of the Broyden-Fletcher-Goldfarb-Shanno algorithm of the function optim in R (version

207 3.0.3). Half-saturation constants for nitrogen uptake could not be determined because of the missing estimates of the maximum nitrogen uptake rate. 
210 Design of competition experiments:

211 We investigated the competition between the toxic and non-toxic strain under $\mathrm{N}$ - and P-

212 limitation and three different nutrient supply regimes: i) Competition experiments under 213 constant supply were conducted in chemostats (continuous cultures) of $470 \mathrm{~mL}$ culture

214 volume with a constant dilution rate of 0.1 day $^{-1}$ ("continuous supply"). The set up and 215 maintenance of the chemostats followed the same methodology as described previously

216 (Fussman et al., 2000; Hiltunen et al., 2013), and all containers used during the experimental 217 procedures were washed with $2 \% \mathrm{HCl}$. Chemostat cultures were started as follows: both 218 genotypes were grown in monocultures into steady state, cell densities were enumerated and 219 then both genotypes were mixed in equal proportion. ii) Competition experiments under 220 pulsed nutrient supply were run as semi-continuous cultures, using $1000 \mathrm{~mL}$ Erlenmeyer 221 flasks that contained $500 \mathrm{~mL}$ of culture. For the experiments with short pulse intervals, $10 \%$ 222 of the culture was replaced every third day with fresh growth medium (" 3 -day-interval223 pulse"). iii) For the experiments with a single large pulse, $10 \%$ of the mixed culture was 224 replaced on the first day with fresh growth medium ("single-pulse"). Subsequent 225 replacements occurred every third day, where $10 \%$ of the mixed culture was replaced with fresh growth medium devoid of nitrate or phosphate, respectively. Experiments were carried out in Z8 culture medium without chloramphenicol and with varying nitrogen $(\mathrm{N})$ and

228 phosphorus (P) concentrations, depending on the type of nutrient limitation and supply 229 regime. An overview of the different types of experiments and their corresponding nutrient 230 supply concentrations and supply regime is given in Table 1 . In the two different pulsed 231 experiments, the total amount of limiting nutrient provided during the course of the 232 experiment was the same. All experiments were replicated at least three times and were 233 initially inoculated at a 1:1 ratio of toxic versus non-toxic strain cells. Light was unidirectional, with 90-100 $\mu \mathrm{mol}$ photons $\mathrm{m}^{-2} \mathrm{~s}^{-1}$ intensity. Furthermore, in all experiments, 
the light intensity measured at the backside of the culture vessels was $35 \mu \mathrm{mol}$ photons $\mathrm{m}^{-2}$

$236 \mathrm{~s}^{-1}$ or higher, which indicates that light availability within the culture was growth-saturating

237 (Hesse et al., 2001; Huisman et al., 2002). Light intensity was measured with a model LI-250

238 light meter (LI-COR, Lincoln, NE, USA).

239 Statistics:

240 We used Student's $t$-test to investigate the effect of genotype identity on the different

241 nitrogen and phosphorus parameters, and we used a repeated measures ANOVA

242 (RMANOVA) to investigate the effects of growth medium and supply regime on Microcystis 243 cell density. All analyses were performed with PASW statistics (SPSS Inc. Chicago IL, v. $24420.0)$ software.

Mathematical model and numerical simulations:

247 Many phytoplankton species take up nutrients such as nitrogen and phosphorus in excess when these resources are abundant and store them intracellularly until periods of low nutrient availability arise. Therefore, we use a variable-internal-stores model ("Droop-model") in order to investigate the effect of nutrient fluctuations on the competition between two Microcystis genotypes (Droop, 1973). This model has been analyzed previously by Grover (1991) and will therefore be explained here only in brief. The model assumes a spatially homogeneous habitat, such as a well-mixed chemostat. The population density of a specific genotype, $N_{i}$, increases with a certain specific growth rate, $\mu_{i}$, and it decreases with a constant rate, $D$, the chemostat dilution rate. The specific growth rate of a genotype depends on its

256 intracellular phosphorus pool, $Q_{i}$, which increases with the specific uptake rate, $v_{i}$, and 257 decreases due to cell division. 
258 The phosphorus concentration in the water, $R$, increases due to a constant inflow of 259 phosphorus from the supply vessel and decreases due to chemostat dilution and uptake by 260 phytoplankton cells. The dynamics of $N_{i}, Q_{i}$ and $R$ in the chemostat are then given by

$262 \quad \frac{d N_{i}}{d t}=\mu_{i}\left(Q_{i}\right) N_{i}-D N_{i}$

$263 \frac{d Q_{i}}{d t}=v_{i}\left(R, Q_{i}\right)-\mu_{i}\left(Q_{i}\right) Q_{i}$

$264 \quad \frac{d R}{d t}=D\left(R_{\text {in }}-R\right)-\sum_{i=1}^{2} v_{i}\left(R, Q_{i}\right) N_{i}$

266 Here, $R_{\text {in }}$ defines the supply concentration of phosphorus. The specific growth rate of strain $i$, $\mu_{\mathrm{i}}$, is a saturating function of the internal phosphorus quota, and is given by

$\mu_{i}=\mu_{\max , i}{ }^{\prime}\left(1-\frac{Q_{\min , i}}{Q_{i}}\right)$,

270

where $\mu_{\max , i}$ ' denotes the maximum specific growth rate of strain $i$ and $Q_{\min , i}$ denotes the persistence quota, i.e. the phosphorus concentration inside the cell of strain $i$ at which growth ceases (i.e. where $\left.\mu\left(Q_{\min }\right)=0\right)$. Note, that the maximum specific growth rate, $\mu_{\max , i}{ }^{\prime}$, is never reached because phosphorus quotas do not increase infinitely. Instead, the realized maximum specific growth rate, $\mu_{\max , i}$, which is reached at the point where the phosphorus quota is at its maximum, $Q_{\max , i}$, is always lower. The phosphorus uptake rate of strain $i, v_{i}$, is given by

$278 \quad v_{i}=v_{\max , i}\left(\frac{R}{K_{i}+R}\right)\left(\frac{Q_{\max , i}-Q_{i}}{Q_{\max , i}-Q_{\min , i}}\right)$,

280 where $K_{i}$ describes the half-saturation constant of genotype $i$ for phosphorus uptake. Thus, $v$ increases with the external phosphorus concentrations as described by the Michaelis-Menten- 
282 function and it decreases with increasing intracellular phosphorus quota. For each genotype,

283 the model parameters were measured in monocultures, except for the half-saturation

284 constants for phosphorus uptake, $K_{i}$, which were estimated by the curve-fitting method as 285 describe above. The parameterized model was then used to investigate the competition for a 286 large number of different phosphorus pulse heights and pulse frequencies numerically. In 287 total, simulations were run for $251 \times 351=88101$ different combinations of pulse height and 288 pulse period in the range of $10^{-2}(=0.01)$ and $10^{0.5}(=3.16) \mu \mathrm{mol} \mathrm{P} \mathrm{L}-1$ and of $10^{-2}(=0.01)$ 289 and $10^{1.5}(=31.6)$ days. Note that to be comparable with the experimental results, the model 290 simulations were not run until the final outcome of competition was observed, but they were 291 stopped after 40 days. The observed genotype frequencies at this time point were categorized 292 and the result was drawn on the plane of pulse height and frequency (Fig. 2).

294 Results

\section{Monocultures:}

296 Nitrogen parameters: The monoculture experiments revealed that the toxic and the non-toxic

297 Microcystis genotype differed in their growth and resource utilization traits. Under nitrogen-

298 limited conditions, the critical nitrogen concentration, $R^{*}{ }_{N}$, of the toxic genotype measured in 299 chemostats at steady state was clearly lower than that of the non-toxic strain $(t$-test: $t(6)=$ $3007.56, p<0.001)$. The toxic genotype also exhibited a higher maximum growth rate, $\mu_{\max }(t-$ 301 test: $t(10)=-3.81, p=0.003)$. Even though we do not have replication required for statistical

302 testing, it appears that the WT also had a lower minimum nitrogen quota, $Q_{\min , N}$, and a higher 303 maximum nitrogen quota, $Q_{\max , N}$, compared to the non-toxic genotype (Table 2).

304 Unfortunately, we do not have estimates for the maximum nitrate uptake rate because the uptake experiments failed due to technical problems. Consequently, it was also not possible 
306 to estimate the half-saturation constant for nitrate uptake, $K_{N}$, with the help of curve fitting, as

307 the two parameters are interdependent.

308

309 Phosphorus parameters: Under phosphorus-limited conditions, the critical phosphorus

310 concentration, $R_{P}{ }^{*}$, of the toxic genotype measured in chemostats at steady state was higher

311 than of the non-toxic genotype ( $t$-test: $t(3)=-5.0, p=0.015)$. The toxic genotype also had a

312 higher maximum specific growth rate than the non-toxic genotype (Grover, 1990, 1991; $t$ -

313 test: $t(10)=-2.56, p=0.028)$. In contrast, the non-toxic strain had a higher maximum uptake

314 rate for phosphorus, higher maximum phosphorus quota, and a slightly lower minimum

315 phosphorus quota.

316

317 Competition dynamics:

318 Nitrogen-limitation: The replicated competition experiments under nitrogen-limitation

319 revealed very consistent results. Under constant supply, the total cell density remained

320 constant throughout the experiment (Fig. 1A). Yet, the relative frequency of the toxic

321 genotype gradually increased until it reached 1 after approximately 40 days.

322 Correspondingly, the relative frequency of the non-toxic genotype decreased until it was

323 washed out within the same time period. Thus, under constant nitrogen supply, the toxic

324 genotype clearly outcompeted the non-toxic genotype. When nitrogen was supplied in pulses

325 every three days, the total cell density increased in the beginning of the experiments and

326 reached a constant density after 15 days. The relative frequency of the toxic genotype showed

327 a steep increase within the first six days of the experiment, followed by a more moderate rise

328 until it completely dominated the culture after 24 days. By definition, the relative frequency

329 of the non-toxic genotype exhibited the opposite pattern. When nitrogen was supplied as a

330 single large pulse at the beginning of the experiments, the dynamics of the total cell density 
331 showed a hump-shaped curve (Fig. 1C). The relative frequency of the toxic genotype rose

332 steeply in the beginning and reached $100 \%$ after 9 days, while the non-toxic genotype was

333 washed out.

335 Phosphorus limitation: The total cell density in the experiments with constant phosphorus

336 supply remained constant throughout the experiments and did not differ from the experiments

337 with constant nitrogen supply (Fig. 1A,D; average cell density during the experiment, N-

338 limitation: $6.43 \pm 0.49 \times 10^{6}$ cells $\mathrm{mL}^{-1}$; Fig. 3D; P-limitation $6.31 \pm 0.39 \times 10^{6}$ cells $\mathrm{mL}^{-1}$;

339 RMANOVA $\left.F_{1,5}=0.034, p=0.860\right)$. Yet, the relative genotype frequencies showed

340 considerable variation between replicates. Although the critical phosphorus concentrations

341 measured in monocultures suggested that the non-toxic genotype should win the competition,

342 three competition experiments showed that the non-toxic genotype increased in relative

343 frequency or outcompeted the toxic mutant, while two competition experiments showed

344 coexistence of both genotypes at approximately equal frequencies. Yet, the replicate

345 experiments showed consistent results in the pulsed experiments. In the 3-day-interval-pulse

346 experiments, the total cell density remained constant throughout the experiment and did not

347 differ from the constant supply experiment. Both genotypes coexisted at approximately equal

348 densities for 27 days. (Fig. 1E). In the single-pulse experiments, the total cell density showed

349 a hump-shaped curve, and both genotypes coexisted again at approximately equal densities 350 (Fig. 1F).

Rate of competitive exclusion:

353 As described in the previous section, the nutrient supply regime affected the rate of 354 competitive exclusion, whereby the effect depended on the type of nutrient limitation. We

355 therefore plotted the natural logarithm of the ratio of mutant to wild type relative frequencies 
356

357

358

359

360

361

362

363

364

365

366

367

368

369

370

371

372

373

374

375

376

377

378

379

380

versus time, and calculated the rate of competitive exclusion from the slope of the linear regression line (see e.g. van de Waal et al., 2011). In the nitrogen-limited experiments, the rate of competitive exclusion increased with pulse intensity, being slowest under constant supply and fastest when a single large nitrogen pulse was given (Tab. 3; Fig. 1A-C). In the phosphorus limited experiments, competitive exclusion was reversed and was fastest under constant supply, while pulsed phosphorus supply considerably slowed down competitive exclusion (Tab. 3, Fig. 1D-F).

\section{Model predictions concerning competition for phosphorus:}

Because the phosphorus-limited experiments did not provide very clear results, we also investigated competition under phosphorus limitation with the help of numerical simulations using the growth parameters for each genotype measured in monoculture. The results observed after 40 days show that the non-toxic genotype wins the competition under very short pulse intervals and low pulse height in the lower left corner of Figure 2. Because the results are visualized in a log-log plot, the dominance of the non-toxic genotype is actually confined to a rather small parameter space of nearly-constant phosphorus supply. The dominance region of the non-toxic genotype extends further as a fine, narrowing, diagonal band towards the upper right corner of the graph, but then bends off beforehand and continues rising more slowly with increasing oscillations. To the upper left side of this stripe extends a large region of longer pulse intervals but relatively high pulses, where both genotypes are able to coexist for the period of 40 days. In the lower right corner of the graph, the pulses are too seldom and too low so that both genotypes are washed out before the end of the experiments.

\section{Discussion}


381 Our study demonstrates that closely related genotypes of one species can have distinct

382

383

384

385

386

387

388

389

390

391

392

393

394

395

396

397

398

399

400

401

402

403

404

nutrient physiologies. Our study also shows that these physiological differences can have consequences for the growth and competition between these genotypes, which eventually may have a profound impact on the functioning and the toxicity of blooms in nature. We here discuss the physiological and theoretical background and the ecological implications of these results.

\section{Physiological differences of toxic and non-toxic genotypes}

Genetically, the non-toxic mutant genotype used in our study differed from the toxic wild type genotype only due to the deletion of the $m c y B$ gene. Transcription of $m c y$-genes has been shown to be stimulated by light (Kaebernick et al., 2000; Tonk et al., 2005) and a number of recent studies suggest that adaptation to high light conditions and oxidative stress protection might be the primary role of microcystin (Zilliges et al., 2011; Makower et al., 2015; Meissner, Steinhauser \& Dittman, 2015), though also other functions have been suggested (Kaplan et al., 2012). Interestingly, however, our monoculture experiments reveal that the toxic and the non-toxic genotype show significant differences also in other traits, which do not seem to be directly linked to the cellular functions of microcystins that have so far been described. The toxic genotype appeared to have a higher maximum specific growth rate, $\mu_{\max }$, than the non-toxic genotype in both types of growth media (see Tab. 1). Yet, this is in disagreement with Hesse et al. (2001) and Briand et al. (2012), who did not find any difference between the two genotypes. The toxic genotype also had higher maximum quotas for nitrogen, $Q_{\max , N}$, and phosphorus $Q_{\max , P}$, which suggest that it can store more nutrients and that it can maintain high uptake rates over a longer time period (Tab. 1; Grover, 1991). The non-toxic genotype had a lower critical phosphorus concentration, $R_{P}{ }^{*}$, a lower minimum 
405 phosphorus requirement, $Q_{\min , P}$, and a higher maximum phosphorus uptake rate, $v_{\max , P}$, which 406 suggest that it can deal better with constantly low phosphorus concentrations and that it can

407 better exploit small phosphorus pulses. One possible explanation for this result is that 408 microcystin production is costly in terms of ATP, and thus also in terms of phosphorus, 409 because the corresponding gene cluster and enzyme complex need to be maintained active 410 (Bickel, Lyck \& Utkilen, 2000). However, Briand et al. (2106) found in their experiments 411 with the same strains (WT and mutant) under monoculture and co-culture conditions that the 412 mutant which is not able to produce microcystin, produces higher concentrations of the 413 remaining cyanopeptides. In the light of this finding, interpreting the cost of microcystin 414 production is not so straight forward.

415 It is surprising that the toxic genotype also had a lower minimum nitrogen quota, $Q_{\min , N}$, and a 416 lower critical nitrogen concentration, $R_{N}{ }^{*}$, than the non-toxic genotype. Yet, this result has to 417 be taken with care, because the very high $R_{N}{ }^{*}$-values compared to other studies (Brussaard \& 418 Riegman, 1998; Wilken et al., 2013) indicate that something else might have been limiting 419 growth during these measurements as well. In fact, one would expect the toxic genotype to 420 have a higher nitrogen demand because the production of microcystins is costly in terms of 421 nitrogen (e.g. Long et al 2001; Downing et al., 2005; van de Waal et al., 2009, 2010).

422 We do not yet have a clear explanation for the physiological differences found in our study,

423 Yet, it is known that the deletion of the $m c y B$ gene has various consequences for the cell, e.g. 424 for pigmentation and cellular structure (Hesse et al., 2001), but also for the expression of 425 other genes and proteins, which are related to photosynthesis and respiration, energy426 metabolism or carbon-nitrogen metabolism, to name a few (Alexova et al., 2011; Zilliges et 427 al., 2011; Makower et al., 2015). Thus, the intracellular effects of microcystin production 428 seem manifold, and it is therefore likely that it has side-effects on other phenotypic traits as 429 well. 


\section{Competition in pulsed habitats}

432 Our competition experiments show that the distinct nutrient physiologies of the toxic and the

433 non-toxic genotype discovered in the monoculture experiments also have important

434 consequences for their population dynamics. Our results are largely in agreement with common resource competition models (Tilman, 1982; Grover, 1991, 1997). Under constant nutrient inflow competition was won by the affinity-specialist (sensu Sommer, 1984), i.e. by the genotype which had the lowest $R^{*}$-value for the limiting nutrient (Tab. 1; Fig. 1A and D). Interestingly, the toxic and the non-toxic genotype exhibited a trade-off in the competitive ability for nitrogen and phosphorus, which is also commonly observed between phytoplankton species (Edwards, Litchman \& Klausmeier, 2011). On the one hand our results are consistent with Vézie et al. (2002) and Lei et al. (2015) who found higher growth rates of

442 the mutant genotype and a non-toxic strain under phosphorus limitation. On the other hand 443 our results are inconsistent with Vézie et al. (2002) and Briand et al. (2012) who found that 444 the mutant genotype, rather than the wild type, was growing faster under N-limitation, and 445 Lei et al. (2015) did not observe a clear difference. One reason for this discrepancy might be 446 that these studies used batch cultures rather than continuous or semi-continuous cultures,

447 where the dominant species or genotype in the competition does not need to be the affinity448 specialist. Another reason might be that all three experiments differed in the degree of N449 limitation, and that we cannot assure that N-limitation in our experiments was absolute.

450 Under pulsed nutrient inflow resource competition theory predicts that the growth-specialist 451 (sensu Sommer, 1984), i.e. the species with the highest maximum growth rate, $\mu_{\max }$, wins the 452 competition under small (and frequent) nutrient pulses, while the storage specialist (sensu 453 Sommer, 1984), i.e. species with lowest $Q_{\min }$, highest $Q_{\max }$ and highest $v_{\max }$, wins the 
454 competition under large (and unfrequent) nutrient pulses (Grover 1991, 1997). Our monoculture and competition experiments together suggest that the toxic-genotype was the growth- as well as the storage-specialist for both nitrogen and phosphorus (Tab. 1; Fig. B,C,E,F). Thus, under nitrogen limitation, we did not observe a trade-off in the competitive ability under constant and pulsed nutrient inflow. Under phosphorus limitation, however, this trade-off seemed to be existent. Here, the non-toxic genotype was the superior competitor under constant phosphorus inflow (Tab.1, Fig 1D). Under pulsed phosphorus inflow we did not observed a full reversal of competitive dominance, but the non-toxic genotype no longer outcompeted the toxic genotype. Instead, both genotypes coexisted for the duration of the experiment (Fig. 1E,F). Moreover, our simulation results indicate that the dominance of the toxic genotype would further increase with higher phosphorus pulse intensity (results not shown). This result is in agreement with the general observation, that phytoplankton species show a trade-off between the competitive ability under constant and variable phosphorus limitation (Edwards, Klausmeier \& Litchman, 2013).

Previous studies with toxic and non-toxic Microcystis strains have demonstrated distinct competitive abilities under light carbon, nitrogen and phosphorus limitation (Kardinaal et al., 2007; Van de Waal et al. 2011; LeBlanc Renaud et al., 2011; Briand et al., 2012; Lei et al., 2015). Yet, as Briand et al., (2012) and Lei et al. (2015) conducted their studies in batch cultures competition for nitrogen and phosphorus in continuous or semi-continuous culture

473 has not been investigated before. At first sight, our experiments suggest that phosphorus 474 limitation might favor the dominance of non-toxic genotypes, and that microcystin 475 production does not provide a clear benefit under P-limitation. As P-limitation should not 476 affect the reducing power of cells to the same extent as C- or N-limitation (Sterner and Elser, 477 2002), this results is in line with the hypothesis that microcystins are beneficial under 478 oxidative stress (Zilliges et al., 2012, Makower et al., 2015; Meissner et al., 2015). Yet, it has 
479 to be pointed out that the competitive dominance of the mutant genotype under constant 480 phosphorus limitation was rather fragile and seemed to be limited to a very low parameter 481 range of nearly constant conditions, as rather small nutrient pulses already enabled the toxic 482 genotype to coexist. (Fig. 1D, Fig. 2). It therefore remains an open question whether such 483 highly constant conditions occur in natural freshwater systems and whether phosphorus 484 limitation can really mitigate bloom toxicity.

Nutrient limitation in natural blooms

Our experiments suggest that toxic Microcystis genotypes might be better competitors under nitrogen limitation than non-toxic genotypes, while (constant) phosphorus limitation favors non-toxic genotypes. This result is consistent with several field studies showing that low N:P ratios seem to favor toxic Microcystis genotypes over their non-toxic counterparts

491 (Davis et al., 2009; Rinta-Kanto et al., 2009, Gobler et al., 2016). Furthermore, higher 492 microcystin concentrations have been linked to low N:P ratios in four reservoirs in the United States (Harris et al., 2016), indirectly indicating higher frequencies of toxic genotypes. However, our results do not explain why the relative frequency of toxic genotypes has been found to increase with increasing $\mathrm{N}$ concentrations (Yoshida et al., 2005; Davis et al., 2010).

\section{Acknowledgements}

498 We thank Lyudmila Saari and Matti Wahlsten for technical assistance, Prof. Elke Dittmann 499 for providing the mutant Microcystis strain and Riitta Ilola and Jaakko Vaininpää for nutrient analysis and Jouni Jokela for advising with the analysis. We also thank Johannes Cairns for

501 editing the language. This work was funded by University of Helsinki three-year grant 502 (2015-2018) to T.H. and Academy of Finland (project \#106993 to T.H.). 
503

504

505

506

507

508

509

510

511

512

513

514

515

516

517

518

519

520

521

522

523

524

\section{References}

Alexova R, Haynes PA, Ferrari BC, Neilan BA. (2011) Comparative protein expression in different strains of the bloom-forming cyanobacterium Microcystis aeruginosa. Mol Cell Proteomics, 10, M110.003749.

Bickel H, Lyck S, Utkilen H. (2000) Energy state and toxin content: experiments on Microcystis aeruginosa (Chroococcales, Cyanophyta). Phycologia, 39, 212-218.

Briand JF, Robillot C, Quiblier-Lloberas C, Bernard C. (2002) A perennial bloom of Planktothrix agardhii (Cyanobacteria) in a shallow eutrophic French lake: limnological and microcystin production studies. Arch Hydrobiol, 153, 605-622.

Briand E, Gugger M, François JC, Bernard C, Humbert JF, Quiblier C (2008) Temporal variation in the dynamics of potentially microcystin-productin strains in a bloomforming Planktothrix agardhii (cyanobacterium) population. Appl Environ Microbiol, 74, 3839-3848.

Briand E, Escoffier N, Straub C, Sabart M, Quiblier C, Humbert JF (2009) Spatiotemporal changes in the genetic diversity of a bloom-forming Microcystis aeruginosa (cyanobacteria) population. ISME J, 3, 419-429.

Briand E, Bormans M, Quiblier C, Salençon MJ, Humbert JF. (2012) Evidence of the cost of the production of microcystins by Microcystis aeruginosa under differing light and nitrate environmental conditions. PLoS One, 7, e29981.

Briand E, Bormans M, Gugger M, Dorrestein PC, Gerwick WH (2016). Changes in secondary metabolic profiles of Microcystis aeruginosa strains in response to intraspecific interactions. Environ Microbiol 18, 384-400. 
525 Brooks BW, Lazorchak JM, Howard MD, Johnson MVV, Morton SL, Perkins DA, et al.

526

527

528

529

530

531

532

533

534

535

536

537

538

539

540

541

542

543

544

545

546

547 (2015). Are harmful algal blooms becoming the greatest inland water quality threat to public health and aquatic ecosystems? Environ Toxicol Chem, 35, 6-13.

Brussaard CPD, Riegman R (1998). Influence of bacteria on phytoplankton cell mortality with phosphorus or nitrogen as the algal-growth-limiting nutrient. Aquat Microb Ecol $14,271-280$.

Carrillo E, Ferrero LM, Alonso-Andicoberry C, Basanta A, Martín A, López-Rodas V, Costas E (2003) Interstrain variability in toxin production in populations of the cyanobacterium Microcystis aeruginosa from water supply reservoirs of Andalusia and lagoons of Doñana National Park (southern Spain). Phycologia, 42, 269-274.

Chorus I (2001) Environmental factors and microcystin levels in waterbodies. In: Cyanotoxins - Occurrences, Causes, Consequences (Ed. I. Chorus), pp. 159-177. Springer-Verlag, Berlin, Germany.

Davis TW, Berry DL, Boyer GL, Gobler, C. J. (2009) The effects of temperature and nutrients on the growth and dynamics of toxic and non-toxic strains of Microcystis during cyanobacteria blooms. Harmful Algae, 8, 715-725.

Davis TW, Harke MJ, Marcoval M, Goleski J, Orano-Dawson C, Berry DL, et al. (2010) Effects of nitrogenous compounds and phosphorus on the growth of toxic and nontoxic strains of Microcystis during cyanobacterial blooms. Aquat Microb Ecol, 61, $149-162$.

Dittmann E, Neilan BA, Erhard M, Von Döhren H, Börner T. (1997) Insertional mutagenesis of a peptide synthetase gene that is responsible for hepatotoxin production in the cyanobacterium Microcystis aeruginosa PCC 7806. Mol Microbiol, 26, 779-787. 
548 Dittmann E, Fewer DP, Neilan BA (2011) Cyanobacterial toxins: biosynthetic routes and evolutionary roots. FEMS Microbiol Rev, 37, 23-43.

550

Downing TG, Meyer C, Gehringer MM, Van de Venter M. (2005) Microcystin content of Microcystis aeruginosa is modulated by nitrogen uptake rate relative to specific growth rate or carbon fixation rate. Environ Toxicol, 20, 257-262.

Droop MR (1973) Some thoughts on nutrient limitation in algae. J Phycol, 9, 264-272.

Edwards KF, Klausmeier CA, Litchman E (2011) Evidence of a three-way trade-off between nitrogen and phosphorus competitive abilities and cell size in phytoplankton. Ecology, 92, 2085-2095.

Edwards KF, Klausmeier CA, Litchman E (2013) A three-way trade-off maintains functional diversity under variable resource supply. Am Nat, 182, 786-800.

Fussmann GF, Ellner SP, Shertzer KW, Hairston Jr NG (2000) Crossing the Hopf Bifurcation in a live predator-prey system. Science, 290, 1358-1360.

Gobler CJ, Burkholder JM, Davis TW, Harke MJ, Johengen T, Stow CA \& Van de Waal D. B. (2016). The dual role of nitrogen supply in controlling the growth and toxicity of cyanobacterial blooms. Harmful Algae, 54, 87-97.

Grover JP (1988) Dynamics of competition in a variable environment: experiments with two diatom species. Ecology, 69, 408-417.

Grover JP (1990) Resource competition in a variable environment: phytoplankton growing according to the Monod's model. Am Nat, 136, 771-789.

Grover JP (1991) Resource competition in a variable environment: phytoplankton growing according to the variable-internal-stores model. Am Nat, 138, 811-835. 
570 Grover JP (1997) Resource Competition. Chapman \& Hall, London, United Kingdom.

571 Grover JP (2011) Resource storage and competition with spatial and temporal variation in 572 resource availability. Am Nat, 178, E124-E148.

573 Harris TD, Smith VH, Graham JL, van de Waal DB, Tedesco LP, Clercin N (2016). Combined effects of nitrogen to phosphorus and nitrate to ammonia ratios on cyanobacterial metabolite concentrations in eutrophic Midwestern USA reservoirs. Inland Waters 6, 199-210.

Hesse K, Dittmann E, Börner T (2001) Consequences of impaired microcystin production for 578 light-dependent growth and pigmentation of Microcystis aeruginosa PCC 7806. FEMS Microbiol Ecol, 37, 39-43.

Hiltunen T, Jones LE, Ellner SP, Hairston NG (2013) Temporal dynamics of a simple community with intraguild predation: an experimental test. Ecology, 94, 773-779.

Huisman J, Matthijs HCP, Visser PM, Balke H, Sigon CAM, Passarge J, et al. (2002) Principles of the light-limited chemostat: theory and ecological applications. Antonie Leeuwenhoek 81, 117-133.

Huisman J, Matthijs HCP, Visser PM, eds. (2005) Harmful Cyanobacteria. Springer Aquatic Ecology Series 3, Springer, Dordrecht, The Netherlands.

Joehnk KD, Huisman JEF, Sharples J, Sommeijer BEN, Visser PM, Stroom JM (2008) Summer heatwaves promote blooms of harmful cyanobacteria. Glob Chang Biol, 14, 495-512. response of the microcystin biosynthesis gene cluster. Appl Environ Microbiol, 66, 
593 Kardinaal WEA, Tonk L, Janse I, Hol S, Slot P, Huisman J, Visser PM (2007) Competition

594

595

596

597

598

599

600

601

602

603

604

605

606

607

608

609

610

611

612

613

614 for light between toxic and nontoxic strains of the harmful cyanobacterium Microcystis. Appl Environ Microbiol, 73, 2939-2946.

Kononen K, Kuparinen J, Mäkelä K, Laanements J, Pavelson J, Nommann S (1996) Initiation of cyanobacterial blooms in a frontal region at the entrance to the Gulf of Finland, Baltic Sea. Limnol Oceanogr, 41, 98-112.

Kotai J (1972) Instructions for preparation of modified nutrient solution Z8 for algae. Norwegian Institute for Water Research, Oslo. 69, 5.

Kurmayer R, Kutzenberger T (2003) Application of real-time PCR for quantification of microcystin genotypes in a population of the toxic cyanobacterium Microcystis sp. Appl Environ Microbiol, 69, 6723-6730.

Lei L, Li C, Peng L, Han BP (2015) Competition between toxic and non-toxic Microcystis aeruginosa and its ecological implication. Ecotoxicology, 24, 1411-1418.

Long BM, Jones GJ, Orr PT (2001) Cellular microcystin content in N-limited Microcystis aeruginosa can be predicted from growth rate. Appl Environ Microbiol, 67, 278-283.

Makower AK, Schuurmans JM, Groth D, Zilliges Y, Matthijs HC, Dittmann E (2015) Transcriptomics-aided dissection of the intracellular and extracellular roles of microcystin in Microcystis aeruginosa PCC 7806. Appl Environ Microbiol, 81, 544554.

Mantzouki E, Visser PM, Bormans M, Ibelings BW (2015) Understanding the key ecological traits of cyanobacteria as a basis for their management and control in changing lakes. Aquat Ecol, 1-18 10.1007/s10452-015-9526-3 
615 Meissner S, Steinhauser D, Dittmann E (2015) Metabolomic analysis indicates a pivotal role 616 of the hepatotoxin microcystin in high light adaptation of Microcystis. Env Microbiol, $617 \quad 17,1497-1509$.

618 Moisander PH, Steppe TF, Hall NS, Kuparinen J, Paerl HW (2003) Variability in nitrogen 619 and phosphorus limitation for Baltic Sea phytoplankton during nitrogen-fixing 620 cyanobacterial blooms. Mar Ecol Prog Ser, 262, 81-95.

621 O'neil JM, Davis TW, Burford MA, Gobler CJ (2012) The rise of harmful cyanobacteria 622 blooms: the potential role of eutrophication and climate change. Harmful Algae, 14, 313-334.

Padisák J, Reynolds CS, Sommer U eds. (1993) Intermediate Disturbance Hypothesis in Phytoplankton Ecology. Developments in Hydrobiology 81, Kluwer Academic Publishers, Dordrecht, The Netherlands.

Paerl HW, Huisman J (2008) Blooms like it hot. Science, 320, 57-58.

Paerl HW Huisman J (2009) Climate change: a catalyst for global expansion of harmful cyanobacterial blooms. Environ Microbiol Rep, 1: 27-37.

Paerl HW, Otten TG (2013) Harmful cyanobacterial blooms: causes, consequences, and 631 controls. Microb Ecol, 65, 995-1010.

632 Park HD (1998) Temporal variabilities of the concentrations of intra- and extracellular microcystin and toxic Microcystis species in a hypertrophic lake, Lake Suwa, Japan (1991-1994). Environ Toxicol Water Qual, 13, 61-72.

Reynolds CS (1993) Scales of disturbance and their role in plankton ecology. Hydrobiologia, 636 $249,157-171$. 
637 Rinta-Kanto JM, Konopko EA, DeBruyn JM, Bourbonniere RA, Boyer GL, Wilhelm SW

638 (2009) Lake Erie Microcystis: relationship between microcystin production, dynamics

639 of genotypes and environmental parameters in a large lake. Harmful Algae, 8, 665-

$640 \quad 673$.

641 Rohrlack T, Henning M, Kohl J-G (2001) Isolation and characterization of colony-forming

642 Microcystis aeruginosa strains. In: Cyanotoxins-Occurrences, Causes,

643 Consequences (Ed. Rohrlack, T., Henning, M., \& Kohl, J. G.), pp. 152-158. Springer-

$644 \quad$ Verlag, Berlin, Germany.

645 Sabart M, Pobel D, Briand E, Combourieu B, Salençon MJ, Humbert JF, Latour D (2010)

646 Spatiotemporal variation in microcystin concentrations and in the proportions of

647 microcystin-producing cells in several Microcystis aeruginosa populations. Appl

$648 \quad$ Environ Microbiol, 76, 4750-4759.

649 Sivonen K, Jones GJ (1999) Cyanobacterial toxins. In: Toxic cyanobacteria in Water: A

650 Guide to their Public Health Consequences, Monitoring and Management (Eds I.

651 Chorus and J. Bartram), pp. 41-111. Spon, London, United Kingdom.

652 Soetaert KER, Petzoldt T, Setzer RW (2010) Solving differential equations in R: Package

653 deSolve. J Stat Softw, 33, 1-25.

654 Sommer U (1984) The paradox of the plankton: fluctuations of phosphorus availability

655 maintain diversity of phytoplankton in flow-through cultures. Limnol Oceanogr, 29,

$656 \quad 633-636$.

657 Sommer U (2002) Competition and coexistence in plankton communities. In: Competition

658 and Coexistence (Eds. U. Sommer \& B. Worm), pp. 79-108. Ecological Studies, Vol.

659 161, Springer-Verlag, Berlin. 
660 Stal LJ, Staal M, Villbrandt M (1999) Nutrient control of cyanobacterial blooms in the Baltic 661 Sea. Aquat Microb Ecol, 18, 165-173.

662 Sterner RW, Elser JJ (2002) Ecological Stoichiometry: the Biology of Elements from 663 Molecules to the Biosphere. Princeton University Press, Princeton, NJ, USA.

Tilman D (1982) Resource Competition and Community Structure. Princeton University

665 Press, Princeton, NJ, USA.

Tonk L, Visser PM, Christiansen G, Dittmann E, Snelder EO, Wiedner C, et al. (2005) The 667 microcystin composition of the cyanobacterium Planktothrix agardhii changes toward

668 a more toxic variant with increasing light intensity. Appl Environ Microbiol, 71,

669 $5177-5181$.

Van de Waal DB, Verspagen JM, Lürling M, Van Donk E, Visser PM, Huisman J (2009) The ecological stoichiometry of toxins produced by harmful cyanobacteria: an experimental test of the carbon-nutrient balance hypothesis. Ecol Lett, 12, 1326-1335.

Van de Waal DB, Ferreruela G, Tonk L, Van Donk E, Huisman J, Visser PM, Matthijs HC (2010) Pulsed nitrogen supply induces dynamic changes in the amino acid composition and microcystin production of the harmful cyanobacterium Planktothrix agardhii. FEMS Microbiol Ecol, 74, 430-438. al. (2011) Reversal in competitive dominance of a toxic versus non-toxic cyanobacterium in response to rising $\mathrm{CO}_{2}$. ISME J, 5, 1438-1450. lakes. PLoS One, 9, e104325. 
683 Vézie C, Rapala J, Vaitomaa J, Seitsonen J, Sivonen K (2002). Effect of nitrogen and

684

685

686

687

688

689

690

691

692

693

694

695

696

697

698

699

700

701

702

703

704 phosphorus on growth of toxic and nontoxic Microcystis strains and on intracellular microcystin concentrations. Microb Ecol, 43, 443-454.

Visser PM, Ibelings BW, Bormans M, Huisman J. (2015) Artificial mixing to control cyanobacterial blooms: a review. Aquat Ecol 1-19 doi: 10.1007/s10452-015-9537-0

Walve J, Larsson U (2007) Blooms of Baltic Sea Aphanizomenon sp. (cyanobacteria) collapse after internal phosphorus depletion. Aquat Microb Ecol, 49, 57-69.

Welker M, Von Döhren H, Täuscher H, Steinberg CE, Erhard M (2003) Toxic Microcystis in shallow lake Müggelsee (Germany): dynamics, distribution, diversity. Arch Hydrobiol, 157, 227-248.

Wiedner C, Nixdorf B, Heinze R, Wirsing B, Neumann U, Weckesse J (2002) Regulation of cyanobacteria and microcystin dynamics in polymictic shallow lakes, Arch Hydrobiol, 155, 383-400.

Wilken S, Verspagen JMH, Naus-Wiezer S, van Donk E, Huisman J (2013). Comparison of predator-prey interactions with and without intraguild predation by manipulation of the nitrogen source. Oikos 123, 423-432.

Yoshida M, Yoshida T, Takashima Y, Kondo R, Hiroishi S (2005), Genetic diversity of the toxic cyanobacterium Microcystis in Lake Mikata. Environ Toxicol, 20, 229-234. doi: $10.1002 /$ tox. 20102

Zilliges Y, Kehr JC, Meissner S, Ishida K, Mikkat S, Hagemann M. et al. (2011) The cyanobacterial hepatotoxin microcystin binds to proteins and increases the fitness of Microcystis under oxidative stress conditions. PLoS ONE, 6, e17615. 


\section{Legends}

706 Table 1. Nutrient supply concentrations and supply regimes of the different competition 707 experiments. * Please note that these supply rates of the limiting nutrient are only for the 708 beginning of the experiment. After the start of the experiment we did not provide any of the 709 limiting nutrient $(\mathrm{N}$ or $\mathrm{P})$.

711 Table 2. Nitrogen and phosphorus parameters of the toxic and the non-toxic Microcystis 712 genotypes. Values marked with ${ }^{\text {a }}$ were estimated by curve fitting. The maximum nitrogen uptake rate, $v_{\max , N}$, and the corresponding half-saturation constant, $K_{N}$, were not determined

714 due to technical problems.

716 Table 3. Rates of competitive exclusion in the six different competition experiments. Rates

717 (cells $\mathrm{mL}^{-1} \mathrm{day}^{-1}$ ) are calculated as the slope of the linear regression of the relative frequency 718 of the non-toxic mutant versus time. Significant positive slopes indicate competitive exclusion of the wild type by the mutant; significant negative slopes indicate competitive exclusion of the mutant by the wild type. Non-significant slopes indicate coexistence. Significant slopes values $(p<0.05)$ are marked in bold.

Figure 1. Relative frequencies of the non-toxic wild type strain (red line, filled symbols) and the non-toxic mutant (blue line, closed symbols) during competition for nitrogen (panels A-C) and phosphorus (panels D-F) at different levels of nutrient fluctuations: (A, D) nutrients supplied continuously, $(\mathrm{B}, \mathrm{E})$ nutrients pulsed at 3-day-intervals, $(\mathrm{C}, \mathrm{F})$ single large nutrient pulse at the beginning of the experiments. Triangles with green dotted line show total 
728 Microcystis densities (cells $\mathrm{mL}^{-1}$ ). Symbols represent means of four replicate microcosms

729 (except in A, $n=5$ ), and vertical bars show standard error of the mean.

730 Figure 2. Simulation results showing the outcome of competition between the toxic

731 Microcystis wild type PCC 7806 and the non-toxic mcyB-deficient mutant genotype for

732 different periods and heights of phosphorus pulses. Note that to be comparable with the

733 experimental results, the graph shows the state of competition after 40 days rather than the

734 equilibrium outcome.

735

736

737

738

739

740

741

742

743

744

745

746

747

748 
Table 1

$\begin{array}{llllll}\text { Type of } & \text { N-supply } & \text { P-supply } & \text { N:P- } & \text { Pulse height } & \text { Pulse period } \\ \text { experiment } & \text { concentration, } & \text { concentration, } & \text { supply ratio } & (\mu \mathrm{mol} \mathrm{N} \mathrm{or} & \text { (days) } \\ & R_{i n, N}(\mu \mathrm{mol} / \mathrm{L}) & R_{i n, P}(\mu \mathrm{mol} / \mathrm{L}) & \text { P) } & \end{array}$

Continuous supply (chemostat)

$\mathrm{N}$-limited

105

26.25

4

P-limited

192

3

64

3-day-pulse (semi-continuous culture)

$\mathrm{N}$-limited

105

26.25

4

10.5

3

P-limited

160

2.5

64

0.25

3

Single pulse (semi-continuous culture)

$\mathrm{N}$-limited

$1050^{*}$

26.25

$40 *$

105

28

P-limited

160

$25^{*}$

$6.4^{*}$

2.5

28

750

751

752

753

754

755

756

757

758 
Table 2

\begin{tabular}{|c|c|c|c|c|}
\hline Parameter & Description & Unit & WT & $\mathbf{M}$ \\
\hline \multicolumn{5}{|l|}{ Nitrogen } \\
\hline$R_{N} *$ & critical resource concentration & $\mu \mathrm{mol} \mathrm{L}-1$ & 32.08 & 37.08 \\
\hline$\mu_{\max , N}$ & realized maximum specific growth rate & day $^{-1}$ & $0.549 \pm 0.039$ & $0.472 \pm 0.036$ \\
\hline$v_{\max , N}$ & maximum nitrogen uptake rate & fmol cell ${ }^{-1}$ day $^{-1}$ & n.d. & n.d. \\
\hline$K_{N}$ & half-saturation constant for nitrogen uptake & $\mu \mathrm{mol} \mathrm{L} \mathrm{L}^{-1}$ & n.d. & n.d. \\
\hline$Q_{\min , N}$ & minimum intracellular nitrogen content & fmol cell ${ }^{-1}$ & 8.019 & 8.506 \\
\hline$Q_{\max , N}$ & maximum intracellular nitrogen content & fmol cell ${ }^{-1}$ & 18.92 & 16.36 \\
\hline
\end{tabular}

Phosphorus

$R p^{*}$

$\mu_{\max , P}$

$v_{\max , P}$

maximum phosphorus uptake rate

$K_{P}$

$Q_{\min , P}$

minimum intracellular phosphorus content

$Q_{\max , P}$

critical resource concentration

maximum specific growth rate

half-saturation constant for phosphorus uptake

maximum intracellular phosphorus content $\mu \mathrm{mol} \mathrm{L}-1$

day $^{-1}$

fmol cell ${ }^{-1}$ day $^{-1}$

$\mu \mathrm{mol} \mathrm{L}-1$

fmol cell ${ }^{-1}$

fmol cell ${ }^{-1}$
$0.073 \pm 0.016$

$0.03 \pm 0.0$

$0.448 \pm 0.040 \quad 0.398 \pm 0.026$

$3.004^{\mathrm{a}}$

0.285

1.880 $3.004^{\mathrm{a}}$

2.272

0.273

1.210 
Table 3

\begin{tabular}{|c|c|c|c|c|c|c|c|c|}
\hline $\begin{array}{l}\text { Resource supply } \\
\text { regime }\end{array}$ & $\begin{array}{l}\text { Limiting } \\
\text { nutrient }\end{array}$ & $\mathrm{n}$ & Slope* & S.E. & $t$-value & $p$-value & $\begin{array}{l}\text { Outcome of } \\
\text { competition }\end{array}$ & Fig. \\
\hline Constant & $\bar{N}$ & 5 & -0.11 & 0.001 & -12.8 & $<0.0001$ & WT wins & $1 \mathrm{~A}$ \\
\hline Constant & $\mathrm{P}$ & 4 & 0.012 & 0.004 & 3.14 & 0.005 & MT wins & $1 \mathrm{~B}$ \\
\hline 3-day pulse & $\mathrm{N}$ & 4 & -0.144 & 0.015 & -9.80 & $<0.0001$ & WT wins & $1 \mathrm{C}$ \\
\hline 3-day pulse & $\mathrm{P}$ & 4 & -0.001 & 0.002 & -0.59 & 0.559 & Co-existence & $1 \mathrm{D}$ \\
\hline Single pulse & $\mathrm{N}$ & 4 & -0.541 & 0.038 & -14.1 & $<0.0001$ & WT wins & $1 \mathrm{E}$ \\
\hline Single pulse & $\mathrm{P}$ & 4 & 0.004 & 0.002 & 1.77 & 0.087 & Co-existence & $1 \mathrm{~F}$ \\
\hline
\end{tabular}

